\title{
Reflexões sobre corpo, saúde e doença em Merleau-Ponty: implicações para práticas inclusivas
}

\author{
Maria Isabel Brandão de Souza Mendes* \\ Allyson Carvalho Araújo** \\ Maria Aparecida Dias*** \\ José Pereira de Melo ${ }^{* * * *}$
}

\begin{abstract}
Resumo: Neste artigo discute-se sobre corpo, saúde e doença em obras de Maurice Merleau-Ponty, buscando implicações para práticas inclusivas. Problematiza-se o modelo tradicional de saúde e doença, considerados como opostos pautado na concepção biomédica. Problematiza-se a ideia de saúde como ausência de doença, a doença reconhecida como anormalidade e o doente tratado como objeto de intervenções e considerado incapaz. Conclui-se que a compreensão de saúde e doença na perspectiva existencial e sua dimensão afetiva podem colaborar para que os profissionais de saúde tenham um olhar mais amplo sobre a condição humana e sua diversidade.
\end{abstract}

Palavras-chave: Saúde. Doença. Corpo. Fenomenologia. Inclusão.

\section{INTRODUÇÃo}

É notória a relevância das discussões conceituais para qualquer área do conhecimento, principalmente quando refutamos a compreensão de que os conceitos são meras opiniões desvinculadas de qualquer sentido prático. Por defendermos a ideia de que os conceitos expressam algo e que se materializam

\footnotetext{
*Centro de Ciências da Saúde, Departamento de Educação Física, Universidade Federal do Rio Grande do Norte, Natal, RN, Brasil. E-mail: isabelbsm1@gamil.com

**Centro de Ciências da Saúde, Departamento de Educação Física, Universidade Federal do Rio Grande do Norte, Natal, RN, Brasil. E-mail: araujo.allyson@hotmail.com

***Centro de Ciências da Saúde, Departamento de Educação Física, Universidade Federal do Rio Grande do Norte, Natal, RN, Brasil. E-mail: cidaufrn@gmail.com

${ }^{* * * *}$ Centro de Ciências da Saúde, Departamento de Educação Física, Universidade Federal do Rio Grande do Norte, Natal, RN, Brasil. E-mail: melo@digi.com.br
} 
em práticas sociais, nos dirigimos para o campo da saúde, com o intuito de interrogarmos alguns conceitos emblemáticos para a Educação Física.

Surpreendemo-nos quando identificamos poucos estudos na contemporaneidade relacionados às discussões conceituais sobre saúde e doença no Brasil, dentre os quais destacamos os de Ayres (2007); Almeida Filho e Jucá (2002); Boruchovitch e Mednick (2002); Novelli (2001) e Almeida Filho (2000).

Reconhecemos a relevância desses estudos por questionarem o modelo biomédico de saúde e doença e por trazerem contribuições de acordo com os referenciais adotados, numa tentativa de ampliar a compreensão desses conceitos.

Diante da necessidade de ampliar essas discussões a partir de outros referenciais teóricos, almejamos contribuir com esses estudos trazendo à tona uma discussão conceitual, relacionando-a às práticas sociais. Nesse sentido, objetivamos nessa pesquisa discutir sobre corpo, saúde e doença em obras de Maurice MerleauPonty, buscando implicações para práticas inclusivas.

Destacamos aqui, que a escolha por estudos de Maurice Merleau-Ponty deveu-se ao fato desse filósofo ter influenciado de alguma maneira o pensamento de Georges Canguilhem e Michel Foucault, filósofos que contribuíram consideravelmente com discussões no campo da saúde.

A fenomenologia existencial de Merleau-Ponty se pauta num pensamento que busca superar a filosofia da consciência e o positivismo na ciência e tem como fundamento a compreensão de corpo vivo situado no mundo da experiência, que tanto contribuiu para a filosofia de Canguilhem e de Foucault.

Para a discussão realizada sobre corpo, saúde e doença em estudos de Maurice Merleau-Ponty, enfocamos então, três obras do autor: "Fenomenologia da Percepção", "O Olho e o Espírito" e "Conversas".

Movimento, Porto Alegre, v. 20, n. 4, p. 1587-1609, out./dez. de 2014. 
Cabe ressaltar que não tivemos a pretensão de fazer a exegese dessas obras, mas sim, buscar pistas e possibilidades sobre o conceito de saúde e de doença. Para Paul Ricoeur (1976), não é preciso repetir um texto de forma semelhante para a sua compreensão. Ter compreensão é ter a capacidade de produzir novas construções a partir dos sentidos que afloram do texto.

Iniciamos a nossa discussão trazendo elementos sobre a vida de Merleau-Ponty e a compreensão fenomenológica de corpo. Posteriormente, com base nas obras citadas tematizamos a saúde e a doença como fenômenos existenciais e trazemos elementos sobre a dimensão afetiva do ser humano na sua relação com o outro. A seguir traçamos relações entre o doente, suas experiências vividas e suas potencialidades, tendo como foco Paul Cézanne e suas pinturas, como possibilidades de se expressar e de se comunicar. Para finalizar, a partir das discussões realizadas apontamos elementos importantes que podem colaborar com os profissionais da Educação Física a contribuírem com práticas inclusivas. Nas considerações finais enfatiza-se que as discussões tecidas podem colaborar para que esses profissionais tenham um olhar mais amplo sobre a condição humana e sua diversidade.

\section{Sobre Maurice Merleau-Ponty}

Maurice Merleau-Ponty nasceu em 1908 em Rochefort-surMer na França e faleceu em 1961 aos 53 anos. Em 1945 tornouse doutor em Filosofia e em 1948 foi professor da Universidade de Lyon, época em que fez parte da direção da revista Les Temps Modernes, juntamente com Jean Paul Sartre. Foi professor titular de Psicologia Infantil na Sorbonne de 1949 a 1952 e é nesse último ano que foi eleito para a cátedra de Filosofia do Collège de France (MERLEAU-PONTY, 1984).

É conhecido por dedicar seus estudos à Fenomenologia com a preocupação de que a filosofia deveria questionar coisas do cotidiano, do mundo vivido. Sua intenção era contribuir para que

Movimento, Porto Alegre, v. 20, n. 4, p. 1587-1609, out./dez. de 2014. 
a filosofia se tornasse mais concreta. A filosofia na sua concepção deveria voltar-se para o mundo em que vivemos (CARMO, 2002).

Merleau-Ponty recebe destaque no pensamento filosófico francês do pós Segunda Guerra e é considerado um dos principais seguidores de Husserl, entretanto, consegue superá-lo, ao desenvolver reflexões sobre o ser no mundo que problematizam o idealismo, ainda presente no pensamento de Husserl. Tido como um filósofo existencialista impactou a intelectualidade francesa na sua época por considerar o ser humano na sua existência, muito mais que na sua essência, problematizando dessa maneira a metafísica. Para ele, a essência está na existência e o ser humano "é pensado em seu meio natural, cultural e histórico, ou seja, como ser-nomundo, mais do que como ser ideal, privilégio anteriormente dado pela filosofia da consciência" (CARMO, 2002, p. 13).

É autor de inúmeras obras que já foram traduzidas para o português, tais como: "O visível e o invisível"; "Humanismo e Terror"; "Fenomenologia da percepção"; "Ciências do homem e fenomenologia"; "A estrutura do comportamento"; "O primado da percepção e suas consequências filosóficas"; "A prosa do mundo"; "A natureza"; "O olho e o espírito", "Psicologia e Pedagogia da criança", "Signos" e "As aventuras da dialética".

Nas obras de Merleau-Ponty, o corpo constitui-se em um dos principais temas do seu pensamento, assumindo um sentido ontológico. Considera o sujeito como corpo e a consciência encarnada no corpo, no intuito de superar o dualismo cartesiano. Sua intenção é problematizar a ideia de que há um espírito que comanda e que está fora do corpo. Além disso, o corpo não é considerado um objeto isolado, pois está entrelaçado ao mundo em uma situação. É pelo corpo que se conhece o mundo e o mundo é incorporado ao corpo pelas experiências vividas numa relação estesiológica (MERLEAU-PONTY, 1999a; 1999b). Nas palavras de Merleau-Ponty, "Ser corpo, nós o vimos, é estar atado a um certo mundo" (MERLEAU-PONTY, 1999a, p. 205). MerleauPonty destaca ainda que:

Movimento, Porto Alegre, v. 20, n. 4, p. 1587-1609, out./dez. de 2014. 
o corpo nos une diretamente às coisas por sua própria ontogênese, soldando um a outro os dois esboços de que é feito, seus dois lábios: a massa sensível que ele é e a massa do sensível de onde nasce por segregação, e à qual, como vidente permanece aberto (MERLEAU-PONTY, 1999b, p. 132).

Além disso, nem se pode conhecer tudo do corpo humano, nem tudo no corpo é percebido. Há zonas de silêncio. Ao mesmo tempo em que se mostra, o corpo é capaz de se esconder, o que problematiza uma concepção de ciência que defende ser capaz de conhecer tudo do corpo humano. Nesse sentido, essa capacidade do corpo se mostrar e se esconder ao mesmo tempo é reconhecida por Merleau-Ponty como o paradoxo do ser humano (MerleauPonty, 1999a; 1999b).

Apesar de não ter escrito obras específicas para a área da saúde, percebemos que ele traz grandes contribuições para esse campo em seus escritos filosóficos. Merleau-Ponty tece críticas ao pensamento clássico por este operar pelo homogêneo, um pensamento que não considera a diversidade humana, suas singularidades. No seu discurso destaca que o pensamento clássico não apresenta a atenção devida ao animal, à criança, ao primitivo e ao louco. De acordo com o pensamento clássico há um padrão a ser seguido: o do homem adulto sadio:

Tudo acontece como se o pensamento clássico tivesse se mantido preso em um dilema: ou o ser com o qual nos defrontamos é assimilável a um homem, sendo então permitido atribuirlhe por analogia as características geralmente reconhecidas no homem adulto e sadio, ou ele nada mais é do que um mecanismo cego, um caos vivo, e não há então nenhum meio de encontrar um sentido em sua conduta (MERLEAU-PONTY, 2004a, p. 32).

Ao sabermos que Merleau-Ponty refuta esse tipo de pensamento, buscamos tematizar algumas de suas contribuições para o campo da saúde.

Movimento, Porto Alegre, v. 20, n. 4, p. 1587-1609, out./dez. de 2014. 


\section{Saúde e doença como fenômenos existenciais}

Pelo que podemos observar, Merleau-Ponty (1999a) se contrapõe à compreensão de saúde como ausência de doença e à ideia de que esses dois fenômenos são vistos como opostos. Problematiza-se então, o modelo tradicional de saúde e doença pautado na concepção biomédica.

Apesar de relativamente recente, a crítica contundente ao modelo biomédico já se encontra devidamente registrada no campo da produção do saber em saúde (GUEDES et al, 2006), sobretudo no que se que refere à localização da doença no corpo humano e na inserção da anatomia patológica nas práticas médicas.

$\mathrm{Na}$ contracorrente da tradição biomédica, observa-se uma crescente de trabalhos como o de Sousa Campos (2000), Alves e Rabelo (1998) e Souza e Erdmann (2006) que já vem recuperando o pensamento de Maurice Merleau-Ponty para repensar os saberes e práticas no campo da saúde. Especificamente no campo da Educação Física autores como Fernsterseifer (2006) já refletiram a noção de corpo, com base nos posicionamentos do Merleau-Ponty, para a saúde.

Para Merleau-Ponty, a saúde e a doença são fenômenos existenciais. Não são reconhecidos em oposição e nem com hierarquizações. Nas suas palavras destaca que:

[...] doença e saúde não são modalidades da consciência ou da vontade, eles supõem um "passo existencial". A afonia não representa apenas uma recusa de falar, a anorexia uma recusa de viver, elas são essa recusa do outro ou essa recusa do futuro arrancadas da natureza transitiva dos "fenômenos interiores", generalizadas, consumadas, tornadas situação de fato (MERLEAU-PONTY, 1999a, p. 227).

Doença e saúde são fenômenos considerados existenciais que se manifestam no corpo em determinadas situações de vida. Merleau-Ponty também destaca que as alterações da existência

Movimento, Porto Alegre, v. 20, n. 4, p. 1587-1609, out./dez. de 2014. 
variam conforme as relações interpessoais quando ressalta a relação do doente com o seu médico, ou seja, quando fala especificamente de uma relação permeada por confiança e amizade, capaz de contribuir com a recuperação da voz, no caso de um doente afônico.

Como podemos observar em seu estudo, a coexistência, a abertura ao outro ou a algo que lhe fez sentido anteriormente são capazes de transformar existências. Nesse sentido, ao debater sobre a afonia, o filósofo diz que:

o doente recuperará sua voz, não por um esforço intelectual ou por decreto abstrato da vontade, mas por uma conversão na qual todo seu corpo se concentra, por um verdadeiro gesto, assim como podemos procurar e encontrar um nome esquecido não "em nosso espírito", mas "em nossa cabeça" ou "em nossos lábios". A recordação ou a voz são reencontradas quando o corpo se abre novamente ao outro ou ao passado, quando se deixa atravessar pela coexistência e quando novamente (no sentido ativo) significa para além de si mesmo (MERLEAU-PONTY, 1999a, p. 228).

Merleau-Ponty problematiza a superioridade e hierarquização do espírito perante o corpo, como pode ser identificado numa compreensão dicotômica. Para ele, o corpo não é pensado de forma fragmentada, como no pensamento cartesiano. Corpo e mente formam um todo integrado.

Com vistas a superar a hierarquia da consciência e de sua compreensão como uma operação intelectual advinda da decodificação de estímulos dos órgãos dos sentidos, MerleauPonty (1999a) buscou subsídios nos estudos neurológicos de sua época, que buscavam superar a ideia de que o cérebro possuía localizações estáticas.

A compreensão fenomenológica de corpo presente nos estudos de Merleau-Ponty se atualiza com os estudos neurológicos contemporâneos que tratam da plasticidade cerebral e que não operam por dicotomias, como os estudos de Oliver Sacks. Como o referido autor destaca:

Movimento, Porto Alegre, v. 20, n. 4, p. 1587-1609, out./dez. de 2014. 
Os neurocientistas começaram a reconhecer, nos anos 1970, que poderia existir uma certa flexibilidade ou plasticidade no cérebro, pelo menos nos dois primeiros anos de vida. Mas pensavam que, passado esse período crítico, o cérebro tornava-se muito menos plástico.

No entanto, o cérebro permanece capaz de mudanças radicais em resposta a uma privação sensorial (SACKS, 2010, p. 182).

Os estudos neurológicos contemporâneos sobre a plasticidade cerebral reforçam os estudos em que Merleau-Ponty apresenta a capacidade de mudanças que o ser humano tem.

O ser selvagem é o ser do abismo e é apresentado no livro "O visível e o invisível" para caracterizar a ontologia defendida por Merleau-Ponty. Uma ontologia que rompe com uma metafísica dualista e opera por meio da relação entre corpo e mundo, desestabilizando as pretensões científicas e filosóficas que operam por pressupostos determinísticos e absolutos. O ser selvagem, o ser do abismo faz emergir a compreensão de que o corpo humano se modifica constantemente. O corpo humano é aberto e inacabado (MERLEAU-PONTY, 1999b).

Essa capacidade constante do ser humano se transformar observada no corpo vivo que Merleau-Ponty defende também pode ser discutida no processo saúde-doença. Retornando ao exemplo da afonia, percebemos que a recuperação da voz ou da recordação de algo que estava esquecido por meio da abertura ao outro ou a algo e a relação permeada por confiança e amizade seja entre médico e paciente ou entre outro profissional de saúde, nos faz destacar a importância para o doente da dimensão afetiva, tanto para os tratamentos terapêuticos humanizados, quanto para a nossa própria existência.

Pelo que podemos identificar nos escritos de Merleau-Ponty, uma relação entre um profissional de saúde e paciente pautada na confiança e na amizade problematiza a ideia de se querer constantemente afirmar um padrão ideal de ser humano. Nesse 
sentido, cada atitude realizada por cada ser humano, esteja ele doente ou não, deve ser considerada pelos profissionais de saúde como possuidora de um sentido e não ser vista como um mecanismo cego ou um caos vivo.

\section{Descobrindo Potencialidades}

Merleau-Ponty era apaixonado pelas artes em geral e com maior vigor, pelas artes plásticas, a pintura. Em "Olho e o Espírito", Merleau-Ponty (2004b) tece meditações sobre a pintura e escreve com uma linguagem próxima da literária, de cunho poético. Supera a tradição acadêmica do discurso filosófico. Interroga o pensamento puro e se detêm na experiência vivida. Reflete sobre a indissociabilidade da visão e do visível, tendo como eixo o trabalho do pintor. Abre espaço para tecer reflexões sobre a arte e o mundo percebido.

O filósofo ressalta que recorre à pintura porque reconhece que esta nos situa diante do mundo vivido e destaca que:

Em Cézanne, Juan Gris, Braque, Picasso encontramos objetos de diversas maneiras limões, bandolins, cachos de uva, maços de cigarro - que não se insinuam ao olhar como objetos bem conhecidos, mas, ao contrário, detêm o olhar, colocam-lhe questões, comunicam-lhe estranhamente sua substância secreta, o próprio modo se sua materialidade e por assim dizer, 'sangram' diante de nós (MERLEAU-PONTY, 2004a, p. 55).

Pelo fato da pintura nos reconduzir à visão das próprias coisas, Merleau-Ponty defende a ideia de que uma filosofia da percepção que deseje aprender novamente a ver o mundo deve reconhecer a dignidade da pintura e das artes em geral.

É interessante perceber que em seus estudos sobre a pintura, em especial sobre Paul Cézanne e suas pinturas, Merleau-Ponty nos faz identificar contribuições para os estudos sobre a doença e o doente, contrapondo-se à visão clássica.

Movimento, Porto Alegre, v. 20, n. 4, p. 1587-1609, out./dez. de 2014. 
Os estudos de Merleau-Ponty (2004a), ao se deterem sobre Cézanne a partir de suas experiências vividas, contribuem para superar a visão clássica que não dava muita atenção aos estudos sobre as crianças, os animais, os primitivos e os loucos, ou qualquer um que saísse do que era considerado o modelo de um adulto sadio. De acordo com a visão clássica, quando estes eram estudados, eram comparados com o que os distinguiam do modelo do adulto sadio, tido como padrão e eram considerados doentes e sem sentido, em vez de serem compreendidos como viviam em suas experiências no mundo. Nas palavras deste autor:

O conhecimento das crianças e dos doentes permaneceu por muito tempo rudimentar justamente em virtude desses preconceitos: as questões que o médico ou o experimentador lhes colocavam eram questões de homem; procurava-se menos compreender como viviam por conta própria do que calcular a distância que os separava do adulto ou do homem sadio em seus desempenhos comuns (Merleau-Ponty, 2004a, p. 31).

Reconhecemos, então, que Merleau-Ponty (2004b) traz elementos emblemáticos para a problematização da ideia de doença ser reconhecida como anormalidade e o doente tratado como objeto de intervenções e considerado incapaz.

Ao retomarmos um pouco da vida de Cézanne, observamos que o pintor saía completamente da padronização de um modelo de homem que era considerado sadio. Nascido em Aix-en-Provence, na França em 1839, Cézanne morreu em 1906. Era filho de um banqueiro severo e autoritário, que não o apoiava em suas pinturas. $\mathrm{O}$ pintor possuía dúvidas e falta de confiança em si mesmo em relação à suas capacidades artísticas. Era reconhecido como indeciso, depressivo, colérico, impulsivo, possuidor de angústias interiores e com dificuldades de se adaptar às cidades grandes, em especial Paris, preferindo os ares de sua terra natal (DÜCHTING, 2009).

Cézanne também tinha dificuldades de fazer amizades e preferia buscar a solidão. Alguns críticos de arte o chamavam

Movimento, Porto Alegre, v. 20, n. 4, p. 1587-1609, out./dez. de 2014. 
inclusive de louco. Düchting (2009, p. 86) diz que "Cézanne será toda a sua vida um homem assaltado pela dúvida, pela insegurança, incapaz na prática de um contacto humano normal”.

Cézanne perdia os contatos dóceis com os seres humanos. Ele possuía incapacidade de dominar situações novas. Como destaca Merleau-Ponty:

Essa fuga nos hábitos, num meio que não se coloca problemas, essa operação rígida entre a teoria e a prática, entre 'ser fisgado' e uma liberdade de solitário - todos esses sintomas permitem falar de uma constituição mórbida e, por exemplo, como foi dito em relação a El Greco, de uma esquizoidia (MERLEAU-PONTY, 2004b, p. 125).

Mesmo reconhecendo as dificuldades de Cézanne, MerleauPonty não o achava incapaz. Como dizia Merleau-Ponty, a pintura para Cézanne foi seu mundo e sua maneira de existir, apesar dele próprio duvidar de suas capacidades.

Talvez, Merleau-Ponty até acreditasse que suas capacidades artísticas estavam ligadas diretamente a sua condição que fugia de padrão de normalidade, pois não apresentava preconceitos perante o pintor. Merleau-Ponty destacava sim eram as suas potencialidades ao pintar. Ao se dirigir a Paul Cézanne, Merleau-Ponty ressalta que:

há uma relação entre a constituição esquizóide e a obra de Cézanne porque a obra revela um sentido metafísico da doença - a esquizoidia como redução do mundo à totalidade das aparências imobilizadas e suspensão dos valores expressivos, porque a doença cessa então de ser um fato absurdo e um destino para tornar-se uma possibilidade geral da existência humana quando enfrenta de forma conseqüente um de seus paradoxos - o fenômeno da expressão (MERLEAU-PONTY, 2004b, p. 136).

A doença nesse contexto é vista como forma de existência e não como algo negativo, oposto ao que é considerado normal. E a pintura é reconhecida como possibilidade de expressão do ser no

Movimento, Porto Alegre, v. 20, n. 4, p. 1587-1609, out./dez. de 2014. 
instante do momento vivido, como possibilidade de comunicação e como possibilidade de liberdade criadora. Uma liberdade que se manifesta sem romper os vínculos com o mundo. Vínculo este que reinventa a vida, o cotidiano deste sujeito, dando sentido e significado para sua existência.

Os quadros pintados por Cézanne estão relacionados ao contexto em que vivia. O quadro "A montanha Santa Vitória" fazia parte de seu cotidiano, pois se localiza perto de onde morava o pintor. Nesse contexto, Paul Cézanne se expressa por meio da pintura de acordo com a sua percepção sobre o mundo vivido. Ao pintar reinventa seu próprio mundo e a si próprio.

Podemos perceber que os estudos de Merleau-Ponty sobre Cézanne e suas experiências vividas desestabilizam a concepção tradicional de doença pautada no modelo biomédico.

Nesse modelo tradicional, coloca-se em destaque:

a causação natural das doenças, dificultando qualquer expressão mais holística da saúde. O corpo humano é considerado na medicina acadêmica como uma máquina e cada órgão como uma peça. O papel do médico é de atacar a doença, isto é, de consertar os defeitos de um mecanismo enguiçado. Ao concentrar-se em elementos cada vez menores e divididos do corpo, o médico perde de vista o doente e todo o processo de interrelação sócio-cultural, psicossocial e espiritual que permeia qualquer doença (MINAYO, 1988, p. 375).

No modelo tradicional de doença, a doença é vista como anormalidade e o doente tratado como objeto de intervenções é considerado incapaz. Há a necessidade biomédica de corrigir a doença, o que é considerado defeito.

$\mathrm{Na}$ tradição ocidental, o discurso do anormal foi sendo construído historicamente como preconiza Foucault (2001). Do monstro humano da Idade Média, passando pelo indivíduo a ser corrigido nos séculos XVII e XVIII e pela criança que se masturba

Movimento, Porto Alegre, v. 20, n. 4, p. 1587-1609, out./dez. de 2014. 
nos séculos XVIII e XIX. A partir de meados do século XIX, a anormalidade é regida pela teoria da degeneração, provocando a associação a estigmas e a racismos os mais diversos.

Caminhando na contramão do modelo tradicional de doença associada ao anormal, os estudos de Merleau-Ponty sobre Cézanne e suas experiências vividas nos fazem refletir não somente sobre as limitações do pintor, mas principalmente sobre suas potencialidades e singularidades. Nesse pensamento há espaço para o heterogêneo e para a consideração da diversidade humana repleta de idiossincrasias. Nesses estudos, o foco central não é a doença em si, mas o sujeito doente e a sua relação com o mundo vivido.

Coadunando com esse tipo de olhar sobre o sujeito doente, Oliver Sacks sai dos seus consultórios para pesquisar a vida de seus pacientes no mundo vivido por cada um. Em seu livro "Um antropólogo em marte" apresenta histórias de seus pacientes, como ele mesmo diz, histórias de "metamorfoses em estados alternativos do ser, outras formas de vida, não menos humanas pelo fato de serem tão diferentes" (SACKS, 2006, p. 17).

\section{5 (RE)PENSANDO AS PRÁTICAS EM SAÚDE: POR AÇõES INCLUSIVAS.}

Pensar a doença como forma de existência exige de nós um olhar mais amplo sobre os seres humanos e suas idiossincrasias. Estar atento a este fato nos remete a dialogar sobre a seguinte questão: como é possível relativizar o descentramento da normalidade quando o desvio está marcado no corpo? Aqui estamos focando diretamente no corpo deficiente, aquele corpo que por esta condição já é estigmatizado, controlado e incompreendido historicamente.

Contrariando a lógica historicamente construída, gostaríamos de questionar a percepção linear da debilidade e/ou anormalidade do sujeito deficiente. Ao refletir sobre a condição do deficiente Le Breton nos aponta que

Movimento, Porto Alegre, v. 20, n. 4, p. 1587-1609, out./dez. de 2014. 
O homem portador de deficiência lembra, unicamente pelo poder da presença, o imaginário do corpo desmantelado que assombra muitos pesadelos. Ele cria uma desordem à segurança ontológica que garante a ordem simbólica. Quanto mais a deficiência é visível e surpreendente (um corpo deformado, um tetraplégico, um rosto desfigurado, por exemplo), mais suscita a atenção social indiscreta. (LE BRETON, 2006, p. 75)

Acreditamos que essa percepção a cerca do deficiente ancorase no modelo médico que veicula a noção de deficiência à lesão e à incapacidade, subjugando o sujeito deficiente aos cuidados biomédicos. $\mathrm{O}$ modelo médico de deficiência tende a apontar seu foco para a perspectiva da sub-normalidade do sujeito lesionado, no parâmetro com sujeitos sem deficiência.

Nesse cenário, investe-se no pensamento que considera o corpo deficiente como estigmatizado historicamente, pelo parâmetro da normalidade, mas o que defendemos é que o corpo deficiente é um sujeito e deve ser respeitado em suas singularidades. Suas diferenças e distinções do parâmetro da normalidade, tão cara ao modelo biomédico, são descentramentos de uma expectativa de corpo ideal.

A noção de descentramento que trazemos na questão é tributária do pensamento de Stuart Hall (2004) e diz respeito ao deslocamento dos sujeitos que margeiam o ideal das capacidades humanas fixas, mesmo que dialoguem com o lastro de expectativas que decorrem destas. Neste sentido os sujeitos descentrados, para os fins deste debate, podem ser reconhecidos nos deficientes que desviam do regime de normalidade instituído pela concepção biomédica e que a rigor convivem com as resistências sociais em incluí-los em diversas práticas.

Obviamente, tratar da inclusão não se limita apenas a falar em deficiência. Quando atribuímos esta condição de ser incluído a outros aspectos, vamos encontrar as questões sociais, políticas, econômicas, religiosas, de gênero, entre outras. Mas a ideia de 
focar na deficiência perpassa necessariamente a configuração que a sociedade atual determina para o corpo com deficiência, a partir do regime de visibilidade da debilidade humana. Configuração esta que nos reporta a uma compreensão equivocada por parte da maioria das pessoas sobre o que é o corpo com deficiência, suas possibilidades, sua saúde, independente da deficiência e, ainda, o olhar das pessoas que não possuem deficiência sobre elas.

A pessoa com deficiência tem carregado consigo o estigma de uma avaliação negativa pelo fato da diferença. E, nestes termos, considera-se o deficiente como um sujeito fora do parâmetro de normalidade como deliberadamente inferior ou incompleto, a despeito de suas capacidades criativas e expressivas.

Historicamente, ficou registrado que todos os personagens que compunham o grupo das intituladas "estranhezas anatômicas", no século XVII, fizeram parte de mecanismos de divertimentos familiares em feiras livres e outros espaços, tais como museus de cera ou salas de cinema e teatro. A exibição do anormal é elemento central de um conjunto de dispositivos que fazem da exposição das diferenças, estranhezas, deformidades, enfermidades e mutilações do corpo humano o suporte essencial de espetáculos onde se experimentam as primeiras formas de indústrias modernas da diversão de massa (STIKER, 2008).

Nesse cenário, o distanciamento causado entre os espectadores dentro do parâmetro de normalidade anatômica e as morfologias exóticas foi transferido para as práticas sociais posteriormente pela lógica da exclusão social e da reclusão em instituições de tratamento.

No que se refere aos tratamentos dispensados às pessoas fora da norma, um fato que reforça a noção biomédica do tratamento endereçado aos sujeitos com deficiência é a organização da área de estudo que buscou cientificar a compreensão do deficiente a partir do que foge à normalidade. Segundo Courtine (2008), a área de estudo que se baseia nos processos da anatomia comparada e da embriologia, chamada teratologia, busca organizar o conhecimento acerca do deficiente pelo que lhe falta ou lhe é debilitado.

Movimento, Porto Alegre, v. 20, n. 4, p. 1587-1609, out./dez. de 2014. 
A partir desse investimento científico da teratologia cria-se uma classificação rigorosa das anomalias e "a monstruosidade não é mais uma desordem cega, mas uma outra ordem igualmente regular, igualmente subordinada a leis" (HILAIRE apud COURTINE, 2008, p. 289).

A despeito dos esquadrinhamentos que propõem o distanciamento dos deficientes pela marcação da diferença com carga negativa, gostaríamos de apontar uma noção de existência corporal como categoria que possibilita pensar limitações, mas sobretudo pensar em potencialidades.

Ao considerar o corpo, a partir de uma perspectiva fenomenológica, enquanto condição de existência, Eline Porto (2005) destaca a capacidade do mesmo de refazer-se e superar-se em facticidade, nunca negando-se. Na sequência do pensamento, a autora indaga-se: "porque negar o corpo deficiente? Não, não se nega o corpo deficiente, pois, antes de ele ser deficiente, ele é corpo e está presente no mundo como corpo"(PORTO, 2005, p. 39).

Muitas são as pessoas com algum tipo de deficiência que se sobressaem no âmbito das artes, do esporte e no seu cotidiano com um nível de independência muito bom. Mesmo assim, sabemos que a sociedade cobra desses seres humanos que sejam 'normais', que se 'curem' ou que permaneçam em seus lugares para que seus corpos não incomodem, não desafiem, não "espantem", pois não são vistos em si mesmos, mas apenas como uma deficiência. Nesta direção concordamos com Le Breton quando afirma que:

em nossas sociedades ocidentais, o ator que sofre de uma deficiência não é percebido enquanto homem inteiramente, mas a partir do prisma deformante da compaixão ou do distanciamento. Uma tela psicológica se interpõe. Não falamos da deficiência, mas do deficiente, como se pertencesse à sua essência de sujeito ser deficiente ao invés de ter uma deficiência. O homem é reduzido aqui ao mero estado de seu corpo posto como um absoluto; ele é deduzido, de certa forma, da maneira como o seu corpo se apresenta socialmente (LE BRETON, 2011, p. 218).

Movimento, Porto Alegre, v. 20, n. 4, p. 1587-1609, out./dez. de 2014. 
Sendo assim o ser humano com deficiência chama a atenção da sociedade de coisas que esta não deseja ver, sentir, pensar, mas que têm presença garantida entre nós, ou seja, "a precariedade infinita da existência, e desperta a angústia do corpo desmantelado" (LE BRETON, 2011, p. 218).

E como é possível, com esse olhar, redimensionar a questão da doença para os seres humanos com deficiência?

A resposta que nos vem neste momento é que esse redimensionamento deve perpassar pela dimensão afetiva do ser humano em sua relação com o outro. Uma dimensão afetiva diante da pessoa com deficiência.

Nossa proposta é que o olhar que temos sobre a deficiência e sua condição seja modificado. Os profissionais que atuam na Educação Física precisam compreender isso, não somente no que se refere ao corpo com deficiência, mas em relação a todos que necessitem de seus cuidados. Compreender que a dimensão humana ultrapassa os mais atualizados conhecimentos que possamos ter sobre a nossa própria existência. O ser humano, enquanto ser inacabado e inconcluso merece viver suas potencialidades.

Para tanto, elencamos alguns desafios para os profissionais da Educação Física darem atenção à dimensão afetiva do ser humano na sua relação com o outro. Apontamos a necessidade de abrir espaços de contato que favoreçam a configuração de relações permeadas por confiança e amizade, sem o estabelecimento de hierarquizações.

Outro desafio apontado é não ter mais como foco a doença e a busca incessante por querer corrigi-la a qualquer custo mediante o padrão do homem adulto e sadio, como tece críticas Merleau-Ponty ao se referir ao pensamento clássico. Mas sim, olhar para o doente e reconhecê-lo como um sujeito, um corpo vivo situado no mundo de suas experiências. Experiências vividas que devem ser levadas em consideração, em vez de serem ignoradas. Reconhecer que cada ação possui sentido e intencionalidade e que não pode ser vista com desprezo.

Movimento, Porto Alegre, v. 20, n. 4, p. 1587-1609, out./dez. de 2014. 
Destacamos a relevância para os profissionais da Educação Física de estarem atentos às diferentes expressões e formas de se comunicar de cada corpo humano, sem buscar incessantemente comparações com o que é considerado como o modelo ideal. Ressaltamos ainda que também é necessário reconhecer que nem tudo é capaz de ser conhecido, pois existem as zonas de silêncio.

É preciso vislumbrar a capacidade de mudanças que o corpo humano possui e contribuir com o despertar de potencialidades, respeitando os limites de cada um.

Além da problematização de discursos e ações que reforçam estigmas, preconceitos e práticas excludentes, torna-se relevante também abrir espaço para que cada um possa se expressar livremente, permitindo que seus desejos e necessidades aflorem, respeitando-os a partir de suas idiossincrasias.

Desse modo, os profissionais de Educação Física ao despiremse de preconceitos poderão colaborar com a construção de ações inclusivas, que permitam às pessoas que estão fora de um determinado padrão corporal a não se sentirem discriminadas, além de terem possibilidades de se sentirem motivadas e a poder participar de atividades coletivas.

Outro desafio que se propõe para os profissionais de saúde é a necessidade de se oferecer atividades que despertem a liberdade criadora de cada corpo, de modo que possam contribuir para reinventar a vida, o cotidiano de cada um, despertando sentidos e significados em suas existências.

\section{Considerações Finais}

Considerando-se que no presente estudo defendemos a ideia de que os conceitos expressam algo e se materializam em práticas sociais quando são incorporados, realizamos discussões sobre corpo, saúde e doença, a partir de algumas obras de Maurice Merleau-Ponty, buscando implicações para práticas inclusivas.

Movimento, Porto Alegre, v. 20, n. 4, p. 1587-1609, out./dez. de 2014. 
Destacamos a relevância dos estudos de Merleau-Ponty para a Educação Física ressaltando que a compreensão de saúde e de doença numa perspectiva existencial e sua dimensão afetiva problematizam o modelo tradicional em que saúde e doença são considerados como opostos e estão pautados na concepção biomédica. O destaque ao tema vem a reboque da observação de que "o corpo perfeito, aliado ao discurso da saúde e da ideia de competição, sempre esteve povoando o universo da Educação Física, e os seus professores, na maioria das vezes, pautam suas ações pedagógicas no sentido de consolidar tal pensamento [...] Pois o corpo sem defeito é o corpo emblemático para área." (MELO, 2008, p. 390)

$\mathrm{Na}$ intenção de ampliar o pensamento e as práticas da área, a perspectiva existencial problematiza, ainda, a ideia de saúde como ausência de doença e que considera a saúde como sendo superior perante a doença. Esses fenômenos, reconhecidos como formas de existência diferenciados, não são vistos de maneira hierárquica e problematizam a ideia da doença estar associada à anormalidade e o doente tratado somente como objeto de intervenções e considerado incapaz.

Desse modo, a compreensão de saúde e de doença numa perspectiva existencial e sua dimensão afetiva podem colaborar para que os profissionais de Educação Física tenham um olhar mais amplo sobre a condição humana e sua diversidade.

Para o debate da deficiência especificamente, compreensão de saúde e de doença numa perspectiva existencial amplia o debate desse conceito para além de seu modelo médico, no qual "a deficiência é uma consequência natural da lesão em um corpo, e a pessoa com deficiência deve ser objeto de cuidados biomédicos" (DINIZ, 2007, p. 15). A partir da perspectiva médica, ainda hegemônica, o conjunto de representações e práticas de saúde endereçadas ao deficiente reflete assistencialismo a partir do pressuposto de causalidade linear entre lesão/doença e deficiência.

Ampliando o debate, compreensão de saúde e de doença numa perspectiva existencial colabora para que a deficiência não seja

Movimento, Porto Alegre, v. 20, n. 4, p. 1587-1609, out./dez. de 2014. 
entendida como um problema personalizado no sujeito deficiente, mas como consequência dos arranjos sociais pouco sensíveis à diversidade de corpos e, portanto, de múltiplas condições de existências (BAMPI; GUILHEM; ALVES, 2010).

Destacamos, ainda, que essa discussão conceitual pode contribuir para despertar sentidos nos profissionais de Educação Física e problematizar os engessamentos historicamente construídos pelo modelo biomédico que somente tem como foco o corpo humano como objeto de intervenções, desprezando-o como sujeito da existência.

Além disso, os profissionais de Educação Física, ao olharem para cada corpo humano, como forma de existência, em vez de se focarem sobre a doença ou lesão, podem colaborar com a construção de ações inclusivas, capazes de despertar potencialidades e a superar estigmas e preconceitos que estão tão enraizados na sociedade.

Reflexions about body, health and disease in Merleau-Ponty:
implications for practices inclusive
Abstract: This article discusses about body, health and disease
in works of Maurice Merleau-Ponty, seeking implications for
practices inclusive. Problematizes the traditional model of health
and disease, considered as opposites and guided in the biomedical
perspective. Problematizes the idea of health as absence of
disease, the disease recognized as an abnormality and the patient
treated as an intervention and considered incapable. It follows that
the existential understanding of health and disease in an existential
perspective and its affective dimension can collaborate with health
professionals to take a broader perspective on the human condition
and its diversity.
Key-words: Health. Sickness. Body. Phenomenology. Inclusion.

Movimento, Porto Alegre, v. 20, n. 4, p. 1587-1609, out./dez. de 2014. 


Reflexiones sobre el cuerpo, la salud y la enfermedad en
Merleau-Ponty: implicaciones para las prácticas de inclusión
Resumen: Este artículo discute sobre el cuerpo, la salud y la
enfermedad en las obras de Maurice Merleau-Ponty, en busca
de implicaciones para las prácticas inclusivas. Problematiza el
modelo tradicional de la salud y la enfermedad, considerada
como opuestos y cimentados en la concepción biomédica.
Problematiza la idea de la salud como ausencia de enfermedad,
la enfermedad reconocida como una anomalía y el paciente
tratado como objeto de intervención y considerado incapaz. Se
concluye que la comprensión de la salud y la enfermedad en la
perspectiva existencial y su alcance afectivo pueden colaborar con
los profesionales de la salud a tomar una mirada más amplia a la
condición humana y su diversidad.
Palabras claves: Salud. Enfermedad. Cuerpo. Fenomenología.
Inclusión.

\section{REFERÊNCIAS}

ALMEIDA FILHO, N. O conceito de saúde: ponto-cego da epidemiologia?. Rev. Bras. Epidemiol., São Paulo, v. 3, n. 1-3, p. 4-20, 2000.

ALMEIDA FILHO, N; JUCÁ, V. Saúde como ausência de doença: crítica à teoria funcionalista de Christopher Boorse. Ciênc. Saúde Coletiva, Rio de Janeiro, v. 7, n. 4, p. 879-889, 2002.

ALVES, P. C.; RABELO, M.C. (Org.). Antropologia da saúde: traçando identidade e explorando fronteiras [online]. Rio de Janeiro: Relume Dumará, 1998.

AYRES, J.R.C.M. Uma concepção hermenêutica de saúde. Physis, Rio de Janeiro, v. 17, n. 1, p. $43-62,2007$.

BAMPI, L. N. S.; GUILHEM, D.; ALVES E. D. Modelo social: uma nova abordagem para o tema deficiência. Rev. Latino-Am. Enfermagem, Ribeirão Preto, v. 18, n. 4, jul./ago. 2010. Disponível em: <http://www.scielo.br/pdf/rlae/v18n4/pt_22.pdf>.

BORUCHOVITCH, E.; MEDNICK, B.R. O significado de saúde e doença: algumas considerações para a psicologia da saúde. Psico-USF, Itatiba, v. 7, n. 2, p. 175183, 2002.

CARMO, P.S. Merleau-Ponty: uma introdução. São Paulo: EDUC, 2002.

COURTINE, J. O corpo anormal: história e antropologia culturais da deformidade. In: COURTINE, J.; CORBIN, A.; VIGARELLO, G. História do corpo: da revolução à grande guerra. Tradução de João Batista Kreuch e Jaime Clasen. Petrópolis: Vozes, 2008.

Movimento, Porto Alegre, v. 20, n. 4, p. 1587-1609, out./dez. de 2014. 
DINIZ, D. O que é deficiência? São Paulo: Brasiliense, 2007.

DUCHTING, H. Cézanne. Tradução da Casa das Línguas. China: Taschen, 2009.

FENSTERSEIFER, P. E. Corporeidade e formação do profissional na área da saúde. Rev. Bras. Cienc. Esporte, Campinas, v. 27, n. 3, p. 93-102, maio 2006.

FOUCAULT, M. Os anormais. Tradução de Eduardo Brandão. São Paulo: Martins Fontes, 2001.

GUEDES, C. R. et al. A subjetividade como anomalia: contribuições epistemológicas para a crítica do modelo biomédico. Ciência \& Saúde Coletiva, Rio de Janeiro, v. 11, n. 4, p. 1093-1103, 2006.

HALL, S. A identidade cultural na pós-modernidade. 10. ed. Rio de Janeiro: DP \& A, 2005.

LE BRETON, D. Antropologia do corpo e modernidade. Tradução de Fábio dos Santos Creder Lopes. Petrópolis: Vozes, 2011.

LE BRETON, D. A sociologia do corpo. Petrópolis: Vozes, 2006.

MELO, J. P. Educação Física, corpo e inclusão na escola. In: MARTINS, L. A. R.; PIRES, G. N. L. (Org.). Políticas e práticas educacionais inclusivas. Natal: EDUFRN, 2008.

MERLEAU-PONTY, M. Conversas: 1948. Tradução de Fábio Landa e Eva Landa. São Paulo: Martins Fontes, 2004a.

MERLEAU-PONTY, M. Fenomenologia da percepção. 2. ed. Tradução de Carlos Alberto Ribeiro de Moura. São Paulo: Martins Fontes, 1999a.

MERLEAU-PONTY, M. O olho e o espírito. Tradução de Paulo Neves e Maria Ermantina Galvão Gomes Pereira. São Paulo: Cosac Naify, 2004b.

MERLEAU-PONTY, M. O visível e o invisível. 3. ed. Tradução de José Artur Gianotti e Armando Mora d' Oliveira. São Paulo: Perspectiva, 1999b.

MERLEAU-PONTY, M. Textos escolhidos. 2. ed. Tradução de Marilena Chauí. São Paulo: Abril Cultural, 1984.

MINAYO, M.C.S. Saúde-doença: uma concepção popular da Etiologia. Cad. Saúde Pública, Rio de Janeiro, v. 4, n. 4, p. 363-381, 1988.

NOVELLI, P.G. O conceito de Educação em Hegel. Interface, Botucatu, v. 5, n. 9, p. 65-88, 2001.

PORTO, E. Corporeidade do cego: novos olhares. Piracicaba: Editora UNIMEP/ Memmon, 2005.

RICOEUR, P. Teoria da Interpretação: o discurso e o excesso de significação. Tradução de Artur Mourão. Lisboa: Edições 70, 1976. 
Reflexões sobre corpo, saúde e doença em Merleau-Ponty ...

SACKS, O. O olhar da mente. Tradução de Laura Teixeira Motta. São Paulo: Companhia das Letras, 2010.

SACKS, O. Um antropólogo em marte. Tradução de Bernardo Carvalho. São Paulo: Companhia das Letras, 2006.

SOUSA CAMPOS, G. W. Saúde pública e saúde coletiva: campo e núcleo de saberes e práticas. Sociedade e Cultura, Goiânia, v. 3, n. 1/2, p. 51-74, jan./dez. 2000.

SOUZA, A.I. J.; ERDMANN A. L. Contribuições para o conhecimento em enfermagem à luz da fenomenologia da percepção de Merleau-Ponty. Rev Gaúcha Enferm, Porto Alegre, v. 27, n. 2, p. 166-175, 2006.

STIKER, H. Nova percepção do corpo humano enfermo. In: COURTINE, J.; CORBIN, A.; VIGARELLO, G. História do corpo: da revolução à grande guerra. Tradução de João Batista Kreuch e Jaime Clasen. Petrópolis: Vozes, 2008.

Endereço para correspondência:

Maria Isabel Brandão de Souza Mendes

Universidade Federal do Rio Grande do Norte

Departamento de Educação Física

Campus Universitário Lagoa Nova

59078-970 - Natal - RN

Recebido em: 03.10.2013

Aprovado em: 31.05 .2014

Movimento, Porto Alegre, v. 20, n. 4, p. 1587-1609, out./dez. de 2014. 